\title{
DEVELOPMENT OF THE METHODOLOGY OF THE CHROMATOGRAPHIC DETERMINATION OF NIFEDIPINE IN MEDICINES
}

\author{
LILIYA LOGOYDA ${ }^{1 *}$, DMYTRO KOROBKO ${ }^{1}$, IRYNA IVANUSA ${ }^{1}$, KOVALENKO SERHII ${ }^{2}$
}

${ }^{1}$ Department of Pharmaceutical Chemistry, I. Horbachevsky Ternopil State Medical University, Ukraine. ${ }^{2}$ Department of Organic and Bioorganic Chemistry, Zaporozhye State Medical University, Ukraine. Email: lilya-19@mail.ru

Received: 23 October 2016, Revised and Accepted: 28 November 2016

\section{ABSTRACT}

Objective: The aim was to develop a simple, rapid, less expensive, linear, precise, and accurate reverse phase high performance liquid chromatography method for determination of nifedipine in tablets.

Methods: The chromatographic analysis of nifedipine was performed using liquid chromatograph Agilent 1290 Infinity II LC System. Selected conditions were isocratic elution with binary mobile phase consisting of solution methanol and 0.1\% trifluoroacetic acid (55:45). Detection was carried out using spectrophotometric detector at $265 \mathrm{~nm}$. The method was validated as per ICH guidelines.

Results: The retention time for nifedipine by proposed high performance liquid chromatography (HPLC) method is observed as 3.5 minutes. The correlation coefficients are 1.0000. The developed chromatographic method was found to be accurate with recovery $99.2-99.8 \%$ and was found within the acceptance criteria (i.e. 98.0-102.0\%) with acceptable \% relative standard deviation of not more than $2 \%$ at each level. The assay results of nifedipine in tablets by developed method are highly reproducible, reliable and are in good agreement with the label claim of the medicines (average $99.62 \%)$.

Conclusion: Finally, it should be noted that a new simple, rapid, linear, precise, accurate HPLC method was developed and validated for the determination of nifedipine in medicines in accordance with the ICH guidelines. These results show the method are accurate, precise, sensitive, economic, and rugged. The proposed HPLC method is rapider (retention time is 3.5 minutes). This method can be useful for the routine analysis of nifedipine in pharmaceutical dosage form.

Keywords: Nifedipine, High-performance liquid chromatography, Validation, Linearity, Accuracy, Range of application.

(C) 2017 The Authors. Published by Innovare Academic Sciences Pvt Ltd. This is an open access article under the CC BY license (http://creativecommons. org/licenses/by/4. 0/) DOI: http://dx.doi.org/10.22159/ajpcr.2017.v10i3.15841

\section{INTRODUCTION}

One of the important problems of modern pharmaceutical science is to replenish the range of new medicines and scientific justification of their application in clinical medicine. Increasing the number of antihypertensive medicines and different chemical substances and the need to identify them in present another active pharmaceutical ingredients are constantly put before standardization of medicines and pharmaceutical chemistry task of improving existing and developing new methods of analysis. In this regard, increasing the role of chromatographic methods, and especially - highly efficient options for liquid chromatography (HPLC). Nowadays spectroscopy with liquid and gas chromatography are the most common instrumental methods of analysis. Over the past decade developed spectrophotometric methods for determining amlodipine, nifedipine, verapamil, captopril, fosinopril, diltiazem in substance and dosage forms, and conducted validation and verification spectrophotometric techniques developed in compliance with pharmacopoeias. Along with the unexplored issue is the development of chromatographic methods for analysis of antihypertensive medicines in the standardization of this pharmacological group of medicines [1-6].

Nifedipine, dimethyl 2,6-dimethyl-4-(2-nitrophenyl)-1,4dihydropyridine-3,5-dicarboxylate, is a potent dihydropyridine-type calcium channel blocker which is an antihypertensive medicine. The pharmacopoeial chromatographic conditions are column chromatographic categories L1 (with a fixed phase C18) size of $4.6 \mathrm{~mm}$ $\times 250 \mathrm{~mm}$; mobile phase - acetonitrile:methanol:water (25:25:50); wavelength $-265 \mathrm{~nm}$, flow rate $-1.0 \mathrm{ml} /$ minutes [7]. Our goal was to improve HPLC methods of analysis of nifedipine in medicines $[8,9]$.
The aim of work was the development of simple, expressive, accurate, and less expensive analytical methods for the determination of nifedipine in medicines by HPLC.

\section{METHODS}

Instrumental and analytical conditions

In developing this technique, column Ascentis C18 was used, which has several advantages from a number of columns L1 and provides high speed and high efficiency at a lower pressure system. This reduces the number of used mobile phase that according reduces the cost analysis.

Selected conditions were isocratic elution with binary mobile phase consisting of methanol and $0.1 \%$ trifluoroacetic acid solution in the ratio of 55:45 for optimum peak symmetry of the active ingredient. Besides reducing the analysis time are achieved by increasing the flow rate of $1.5 \mathrm{~mL} /$ minutes and column temperature increase to $35^{\circ} \mathrm{C}$.

The chromatographic analysis of nifedipine performed on liquid chromatograph Agilent 1290 Infinity II LC System.

The brief scheme of the experiment:

- Column: Ascentis express C18 column size $4.6 \mathrm{~mm} \times 150 \mathrm{~mm}$ with a particle size of $5 \mu$;

- Mobile phase: Methanol R - $0.1 \%$ solution of trifluoroacetic acid R (55:45);

- The rate of mobile phase: $1.5 \mathrm{ml} /$ minutes;

- Column temperature: $35^{\circ} \mathrm{C}$;

- Wavelength of the ultraviolet detector: $265 \mathrm{~nm}$. 


\section{Reagents and chemicals}

Nifedipine was obtained as gift sample form company "Zdorovja" (Ukraine). Trade name of nifedipine is "Fenigidin Zdorovja." Tablets were procured from local pharmacy containing $10 \mathrm{mg}$ of nifedipine. Ultrapure water was obtained from a Millipore system. HPLC solvents were obtained from Merck Company. All other chemicals used were AR grade.

\section{Preparation of sample solution}

To $200.0 \mathrm{mg}$ powder pounded tablets, add $10 \mathrm{ml}$ of methanol $\mathrm{R}$, shake in ultrasonic bath for 10 minutes and add methanol $\mathrm{R}$ to the volume of $20.0 \mathrm{ml}$. Filter through a membrane filter with a pore size of $0.45 \mu$, discarding the first $5 \mathrm{ml}$ of filtrate. $2.0 \mathrm{ml}$ of the resulting filtrate adjusted to $20.0 \mathrm{ml}$ of solvent.

\section{Preparation of standard solution}

$20.0 \mathrm{mg}$ of nifedipine SPhU dissolve in methanol $\mathrm{R}$ and dilute with the same solvent to $20.0 \mathrm{ml}$ volume. $2.0 \mathrm{ml}$ of the resulting solution adjusted to $20.0 \mathrm{ml}$ of solvent.

\section{RESULTS}

For elaboration of the method the chromatograms of the standard solution of nifedipine (Fig. 1) and the sample solution of nifedipine (Fig. 2), as well as the dependence of the intensity peaks on the retention time were obtained and analyzed.

The chromatographic system is considered suitable if the following conditions are performed:

- The effectiveness of the chromatographic column, calculated peak of nifedipine should be not $<4000$ theoretical plates;

- Relative standard deviation (RSD) calculated peak area for nifedipine should be not more than $1.0 \%$;

- Symmetry factor calculated on the peak of nifedipine should be $<1.5$.

The content of nifedipine $(X)$ in one tablet, in milligrams, was calculated by the formula. Calculation formula:

$X=\frac{S_{i} \cdot m_{o} \cdot b}{S_{o} \cdot B_{i} \cdot 100}$

Where,

$S_{i}$ - Average of the peak areas of nifedipine, calculated from the chromatograms of the sample solutions;
$S_{0}$ - Average of the peak areas of nifedipine, calculated with the standard solutions chromatograms;

$m_{0}$ - Mass of the sample SPhU nifedipine, in milligrams;

$m_{\mathrm{i}-}$ Mass of the powder pounded tablets, in milligrams;

$P$ - Content of the main substance in SPhU nifedipine as a percentage;

$b$ - Average of weight tablets in milligrams.

\section{Method validation}

Validation of an analytical procedure involves analytical tasks are articulated clearly - for what purpose the analytical procedure is used. We have studied the following validation characteristics: Linearity, accuracy and precision, range of application [10-12].

The statistical quantities and validation parameters were shown in Tables 1 and 2, Figs. 3 and 4.

\section{DISCUSSION}

In the work, a solution containing a mixture of the placebo was prepared using the sample preparation procedure to evaluate possible interfering peaks. The investigated chromatograms did not show any other substances peaks, which prove the specificity of the developed method.

Evaluation of linearity was performed on the range of application of the method using standard method. The results obtained were statistically processed by the least squares method according to the requirements of the SPhU and ICH guidelines. Calculation of the linear relationship $Y=m X+b$ was conducted by the least square method. The linearity plot of nifedipine is found linear and correlation coefficient 1.00000 for nifedipine. This performs that the method is linear in the specified range for the analysis of nifedipine in tablets.

The precision of an analytical procedure expresses the closeness of agreement between a series of measurement obtained from multiple sampling of the same sample under prescribed conditions. Accuracy and precision were studied by method "put-found" on standard solutions of nifedipine. The proposed chromatographic method was found to be accurate with recovery $99.2-99.8 \%$ and was found within the acceptance criteria (i.e., 98.0-102.0\%) with acceptable \% RSD of not more than $2 \%$ at each analyte level. Precision was calculated as repeatability and intraday and interday variation for nifedipine. The proposed method was found to be precise with coefficient of variance $=0.5$ for intraday and interday for nifedipine.

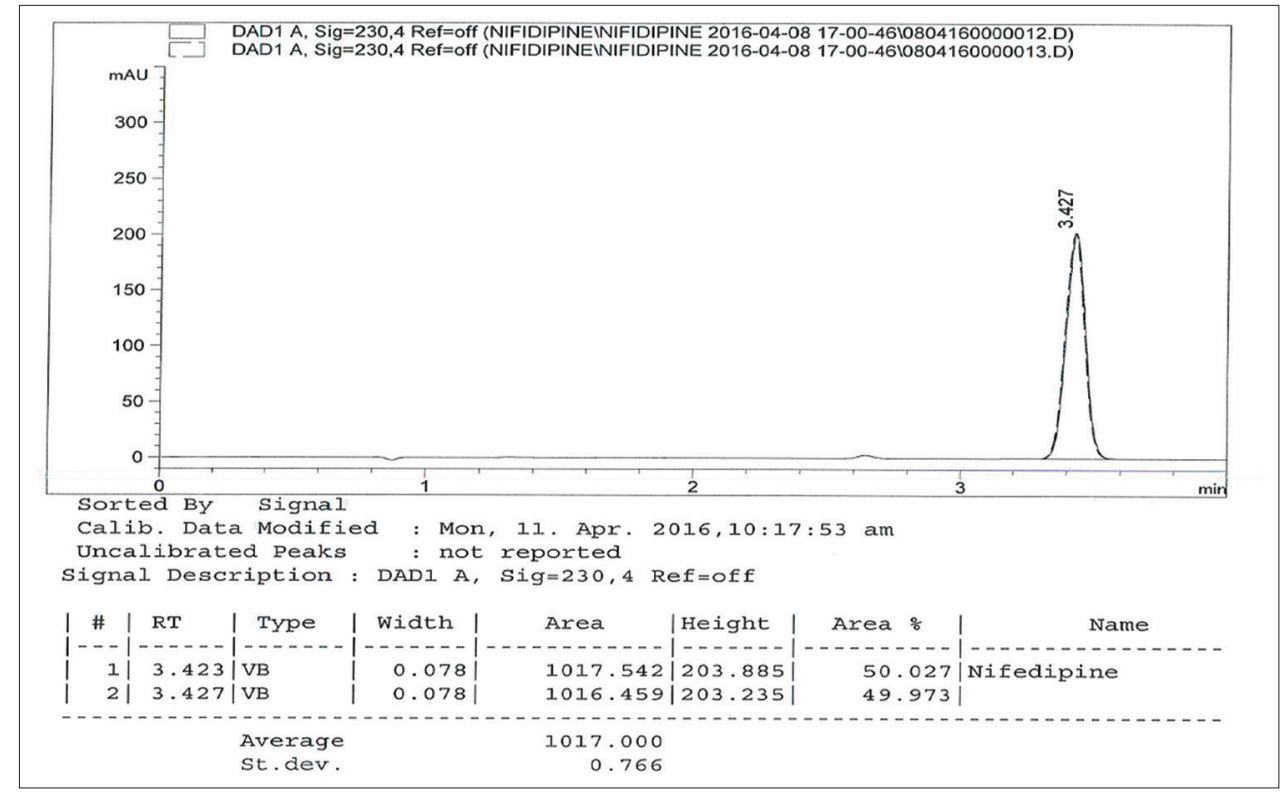

Fig. 1: High performance liquid chromatography chromatograms of the standard solution of nifedipine in the terms of the quantification of nifedipine in tablets 


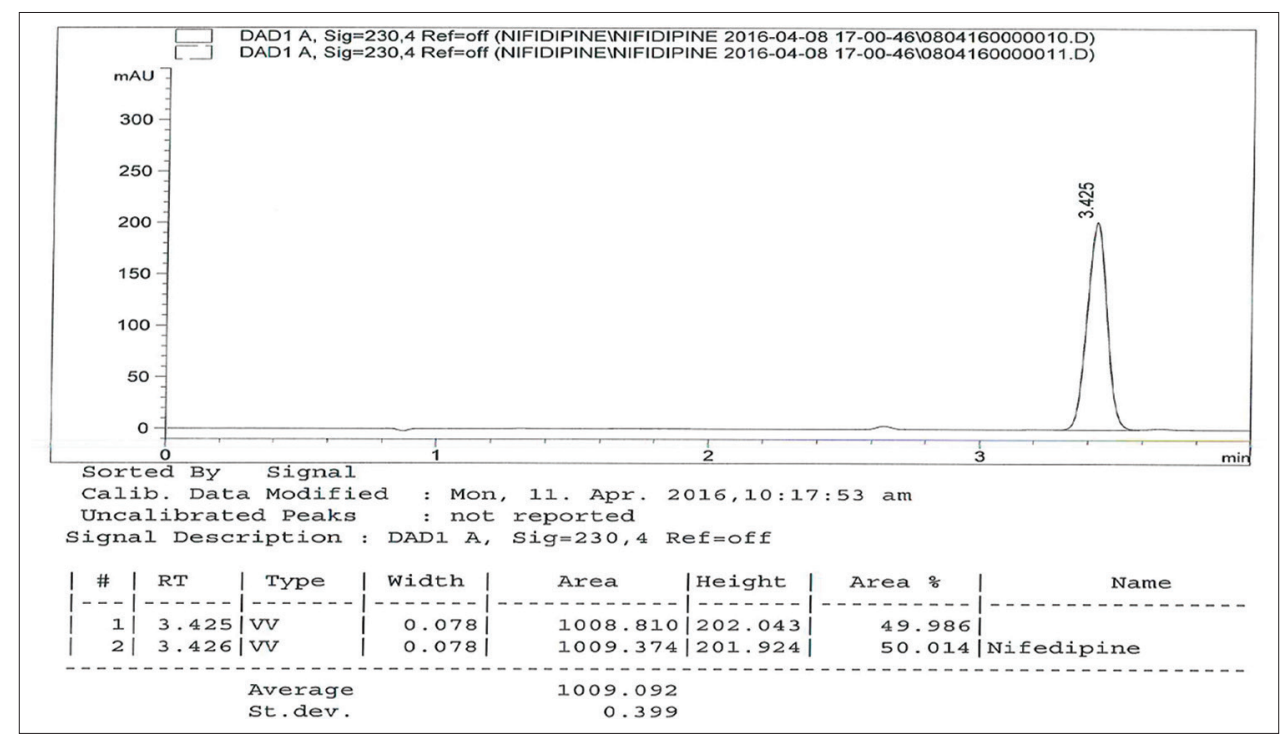

Fig. 2: High performance liquid chromatography chromatogram of the sample solution of nifedipine in the terms of the quantification of nifedipine in tablets

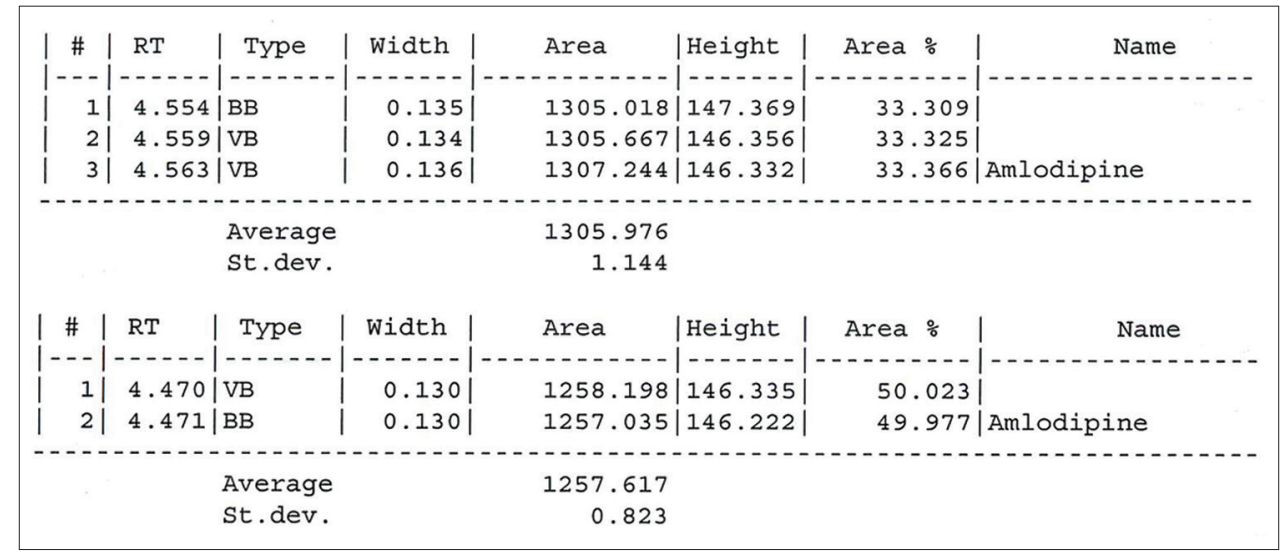

Fig. 3: Resolution of nifedipine in different areas high performance liquid chromatography

Table 1: The results of HPLC determination of nifedipine

\begin{tabular}{|c|c|c|c|}
\hline Model solution & $\begin{array}{l}\text { Amount added } \\
\text { (solution concentration), } \\
\mathrm{mg} / \mathrm{ml}\end{array}$ & $\begin{array}{l}\text { Amount found } \\
\text { (concentration solution), } \\
\mathrm{mg} / \mathrm{ml}\end{array}$ & Recovery, Z, \% \\
\hline RS 1 & 0.1080 & - & - \\
\hline RS 2 & 0.0995 & - & - \\
\hline MS 70\% & 0.0700 & 0.0690 & 98.6 \\
\hline MS $100 \%$ & 0.0995 & 0.0993 & 99.8 \\
\hline MS $130 \%$ & 0.1305 & 0.1300 & 99.6 \\
\hline The average & & & 99.3 \\
\hline The RSD, Sz\% & & & 0.4137 \\
\hline Relative confidence interval, $\Delta \mathrm{z} \%$ & & & 0.99 \\
\hline The critical value for convergence results $\Delta \mathrm{z} \% \leq 3.2$ & & & Conform \\
\hline $\begin{array}{l}\text { The criterion of statistical insignificance } \\
\text { systematic error }\end{array}$ & $\leq 0.33$ & Conform & \\
\hline \multicolumn{4}{|l|}{$\delta \%=|\bar{Z}-100| \leq \Delta_{Z} / \sqrt{\mathrm{n}}$} \\
\hline $\begin{array}{l}\text { Criterion practical insignificance } \\
\text { systematic error }\end{array}$ & $\leq 2.048$ & Conform & \\
\hline \multicolumn{4}{|l|}{$\delta \%=|\bar{Z}-100| \leq 0.32 \Delta_{\mathrm{AS}}$} \\
\hline $\begin{array}{l}\text { General conclusion about procedure } \\
\text { HPLC: High performance liquid chromatography }\end{array}$ & & Conform & \\
\hline
\end{tabular}




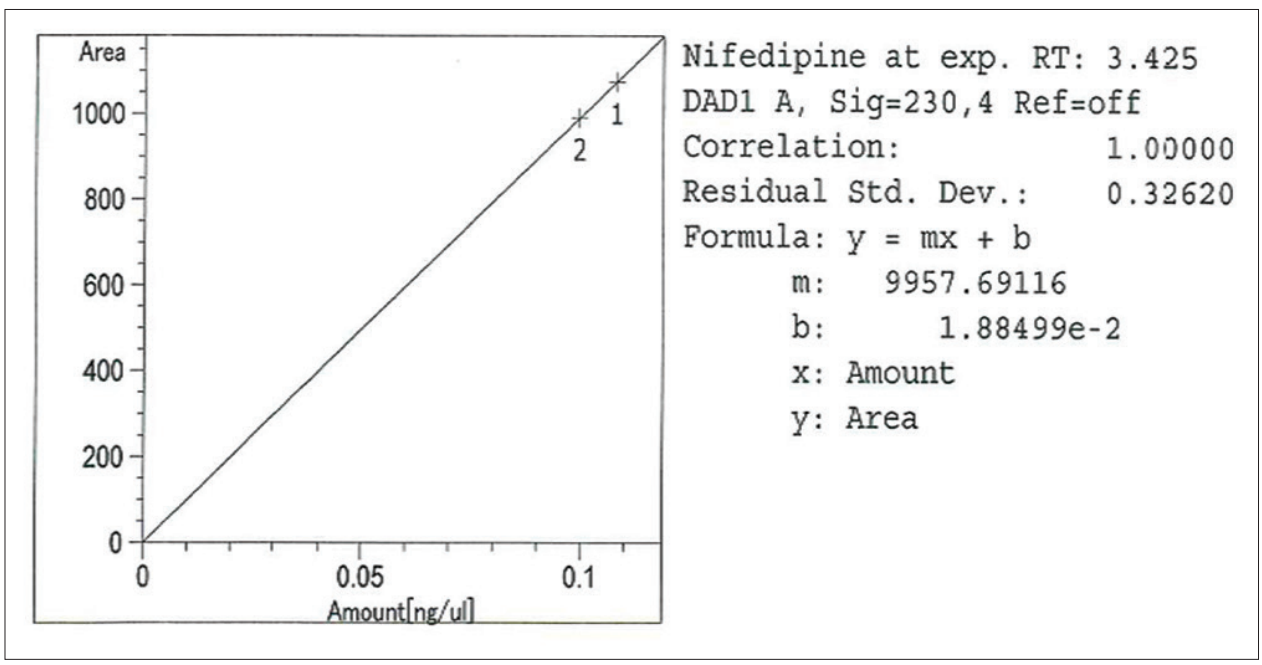

Fig. 4: The linear relationship of the area on nifedipine concentration

Table 2: Summary of validation parameters of nifedipine by proposed HPLC method

\begin{tabular}{ll}
\hline The slope of the linear relationship $b$ & $1.88499 \mathrm{e}-2$ \\
The constant term of the linear & 9957.69116 \\
dependence $m$ & \\
The residual standard deviation $S r$ & 0.32620 \\
The correlation coefficient method $r$ & 1.00000 \\
Accuracy, \% & $99.2-99.8$ \\
Repeatability, (\% assay, n=6) & $99.2-100$ \\
Precision (\% assay) & $101.2-101.8(\% \mathrm{RSD}=0.5)$ \\
Interday (n=3) & $100.3-101.4(\% \mathrm{RSD}=0.5)$ \\
\hline Intraday (n=3)
\end{tabular}

RSD: Relative standard deviation, HPLC: High performance liquid chromatography

Table 3: Assay results

\begin{tabular}{llll}
\hline Sample no & Label claim (mg) & \% Amount found & Average \\
\hline 1 & 10 & 99.8 & 99.62 \\
2 & 10 & 99.6 & \\
3 & 10 & 99.6 & \\
4 & 10 & 99.7 & \\
5 & 10 & 99.4 & \\
6 & 10 & 99.6 & \\
\hline
\end{tabular}

Our study describes new HPLC method using simple chromatographic conditions for the determination of nifedipine in tablets. Under this conditions, the peak of nifedipine elution is about 3.5 minutes.

The assay results of the tablets "Fenigidin Zdorovja" by developed chromatographic method are highly reproducible, reliable and are in good agreement with the label claim of the medicines (average $99.62 \%$ ) (Table 3). This demonstrated excellent result.

\section{CONCLUSION}

Finally, it should be noted that a new simple, rapid, linear, precise, accurate HPLC method was developed and validated for the determination of nifedipine in medicines in accordance with the ICH guidelines. These results show the method is accurate, precise, sensitive, economic, and rugged. The proposed HPLC method is rapider (retention time is 3.5 minutes). This method can be useful for the routine analysis of nifedipine in pharmaceutical dosage forms.

\section{ACKNOWLEDGMENTS}

We are very thankful to authorities of I. Ya. Horbachevsky Ternopil State Medical University (Pharmaceutical faculty) for providing the facilities to complete this research work

\section{REFERENCES}

1. Siddiqui MR, AlOtthman ZA, Rahman N. Analytical techniques in pharmaceutical analysis: A review. Arabian J Chem 2013;138:1395-404.

2. Katz E. Quantitative Analysis Using Chromatographic Techniques. New York: John Wiley \& Sons; 2009. p. 1-427.

3. Nageswara Rao R, Nagaraju V. An overview of the recent trends in development of HPLC methods for determination of impurities in drugs. J Pharm Biomed Anal 2003;33(3):335-77.

4. Bakar RA, Miran H. Validated high performance liquid chromatography (HPLC) method for analysis of methamphetamine in human urine using liquid-liquid extraction. Asian J Pharm Clin Res 2015;8(2):199-201.

5. Patil R, Deshmukh T, Patil V, Khandelwal K. Review on analytical method development and validation. Res Rev J Pharm Anal 2014;3(3):1-10.

6. Handler J. Quality of life and antihypertensive drug therapy. J Clin Hypertens (Greenwich) 2005;7(5):274-85.

7. United States Pharmacopoeia (USP). Medicare Prescription Drug Benefit Model Guidelines Source Information. Available from: http:// www.nlm.nih.gov.

8. State Pharmacopoeia of Ukraine. State Enterprise Ukrainian Scientific Center Pharmacopoeia Quality Medicines. $2^{\text {nd }}$ ed. Vol. 3. Kharkiv: State Enterprise Ukrainian Scientific Center of Quality Pharmacopoeia of Medicines; 2014. p. 724.

9. State Pharmacopoeia of Ukraine/State Enterprise. Scientific and Expert Centre Pharmacopoeia, Appendix 2. $1^{\text {st }}$ ed. Kharkiv: State Enterprise Ukrainian Scientific Center of Quality Pharmacopoeia of Medicines; 2008. p. 620

10. Logoyda L. Validation of chromatographic methods of analysis for the determination of active pharmaceutical ingredients in different medicines. Mansoura University (Egypt): Pharma School Association for Pharmaceutical Development and Scientific Research; 2016. p. 34.

11. ICH. Q2A Text on Validation of Analytical Procedures. Geneva: International Conference on Harmonization; 1994.

12. ICH. Q3B Validation of Analytical Procedures: Methodology. Geneva: International Conference on Harmonization; 1996. 